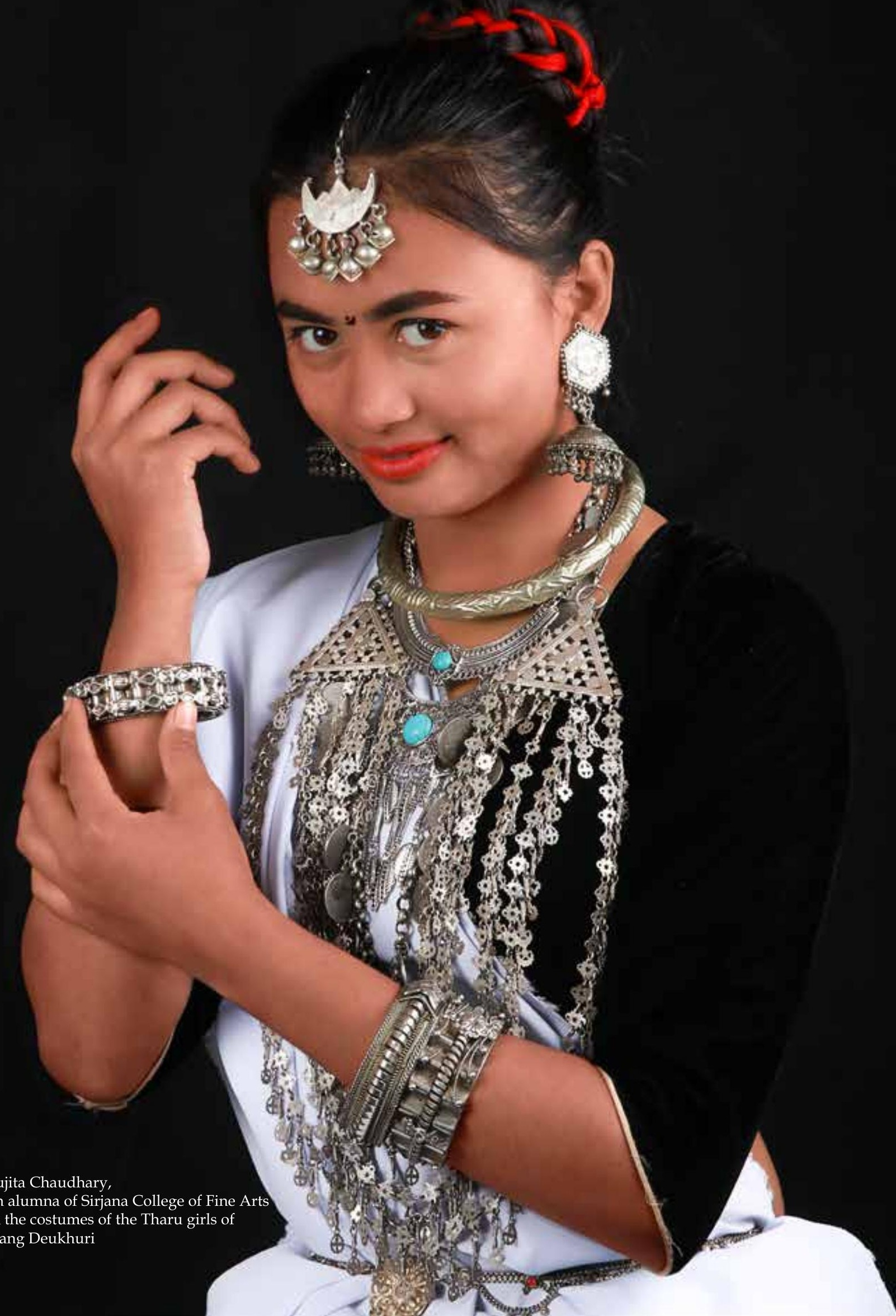




\title{
SYMBOLIC VALUES BEHIND ART IN THE ANIMISTIC PRACTICES AMONG THE THARUS OF DANG AND DEUKHURI
}

\author{
Poonam R. L. Rana, PhD \\ Associate Professor \\ Central Department of Nepalese History, Culture, and Archaeology, TU
}

\begin{abstract}
The symbolic values behind the art in the animistic practices among the Tharus of Dang and Deukhuri is a paper that deals with various symbolic objects, that are termed as fetish associated with the animistic practices observed by the Tharus of Dang and Deukhuri of Terai Nepal. The objects or the fetish created by them when analyzed through an artistic perspective, seems, to the outsiders or through the 'Etic Approach' just a local ethnic crude handicraft. However, when analyzed through the 'Emic Approach' these artistic creations or fetish have great symbolic values associated with it. This paper-based on a field survey of the two regions has brought to limelight the symbolic values behind artistic creativity associated with their animistic practices.
\end{abstract}

Keywords: animism, symbolic values, fetishism

\section{Introduction}

A symbol may be a representation or a sign, it can be a medium to represent words, gestures, ideas, objects, or visual images that may bring forth or represent ideas, beliefs, and values.

The symbolic values and its meanings are intangible, it is benefitted to those who understand the meaning and share the meaning and values associated with it. (http:// www.webesterdictionary) Art is a part of life an activity that has meaning. Its meaning can be symbolic or verbal or visual and Animism is the belief in spirits, ghosts, and souls.

This paper deals with the symbolic values associated with various, objects termed as fetish objects produced in a local artistic crude manner, for those who do not know it is just an 'art object' but to those who belong to the ethnic group, it carries great symbolic values.

Nepal is a country of great diversity in terms of physical topography, ethnic, cultural as well as artistic variation. It is the home place of numerous ethnic 
communities, having their traditions and culture associated with their religious beliefs. It is seen that Nepal and its ethnic communities are the followers of animistic practices, and rituals. This study on the Tharus of Dang Deukhuri is no exception. They are also the followers of Animism, Fetishism, and Mysticism.

\section{Animism}

Sir Edward. B. Tylor, in his book 'In the Primitive Culture' (1871) had defined culture. Tylor's greatest contribution lies in the analysis of 'Anima' or the soul. (Jha, 1983, p. 29 ). He sought also for an explanation of how the belief in spirits could rise. Regarding such views, Tylor termed it as 'Savage Philosophy'. He believed that life enabled the body to think and act, the phantom was its image or second-half. Both were separable from the body; life departed after death, but the phantom could appear to the people at distance, as in dreams. The savages then began to consider the idea of the soul. This made them believe that everything possessed life and souls. And at this early phase, it was known as 'Animism' (Jha, 1983, p.30). This was the early phase of religion.

The primitive men recognized that soul was superior to the body. They believed that it protected their family and tribes. The idea that they resided somewhere, gave the the belief in an afterlife. The concept that these souls could move about and appear anywhere made them think that they could enter any human body and thus began the concept of 'spirit-possession' (Jha, 1983, p 32). They began the worship of 'generalized deities'. Here the researcher focuses on E. B. Tylor's definition and its symbolic values and trys to associate it with the ethnic Tharus of Dang and Deukhuri.

\section{Fetishism}

The word 'fetish' is derived from the French 'fétiche' which comes from the Portuguese word 'feitico' and Latin word 'facticius'. It means 'artificial' or 'to make.' Fetish is an object believed to have some supernatural power. It is a man-made object that has power over others. Fetishism is an emic attribution of inherent value or powers to an object. (www.fetism.org)

Lippert defines fetish as a belief in souls of departed coming to dwell in anything that is tangible or visible in heaven or earth. (Alfred, 1906, p. 46) E. B. Tylor considers Fetishism as a subordinate department to Animism. (Alfred, 1906, p. 71)

Life of the Tharu community of Dang and Deukhuri is associated with animistic practices, fetish and mysticisms. It is an integral part of their livelihood.

\section{Setting/settlement}

Among different ethnic races, Tharu constitute a great bulk of Nepali population - app 458,584. They are dwellers of Terai region of Jhapa in the East, Kanchanpur in the west and in the regions of Bara, Parsa, Rautahat, Sarlahi, Mahottari, Saptari, Morang, Banke, Bardiya, Butwal, Nawalparasi, and Chitwan. However, this study is confined to the villages of Dang and Deukhuri.

As research throughout the region would not have been possible, only two regions have been taken into account in case of the study of the Tharus - the region of Dang and Deukhuri. 


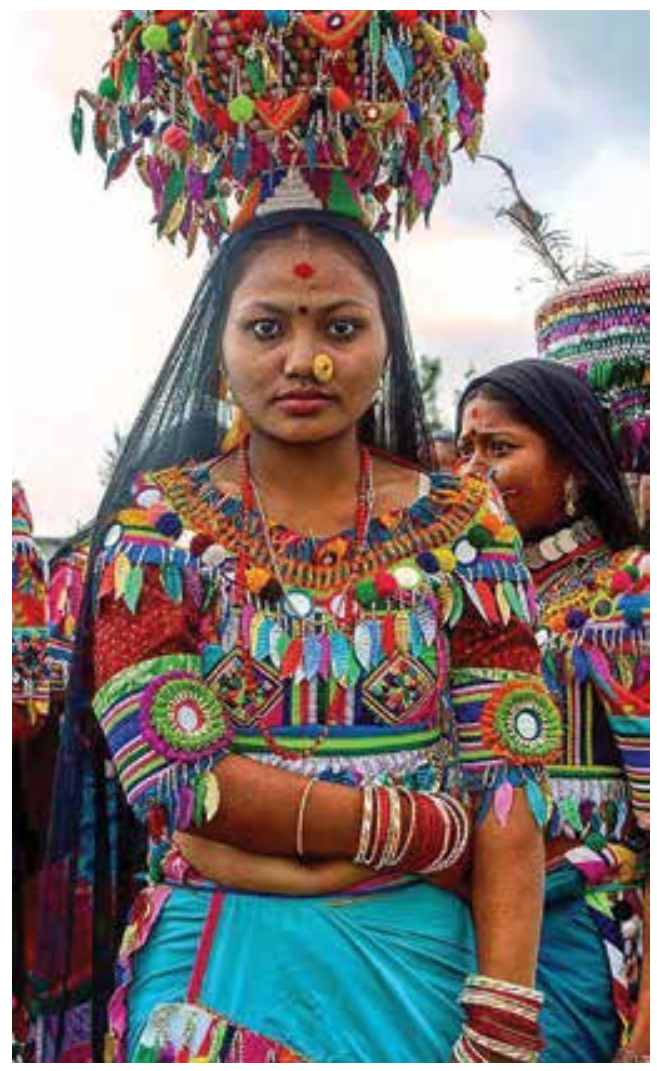

A Tharu Woman from Dang/Deukhuri

\section{Method}

This paper is based on the field survey conducted in different villages of Dang such as Bargati, Digpor, Bhaisai, Puadi, Okra, Karjai. The villages at Deukhuri are - Sisaniya, Arhanpur, Manpur, Pipri, Pipra, Parwa, Paharwa, Pathardgodawa, Majheriya, Baagrapur. The materials published here are based on primary sources. Therefore, one cannot find many references. The materials or data were collected mainly through interviews and observation.

\section{Location}

Dang is located to the west of Nepal. It rises to the height above $6,000 \mathrm{ft}$. forming

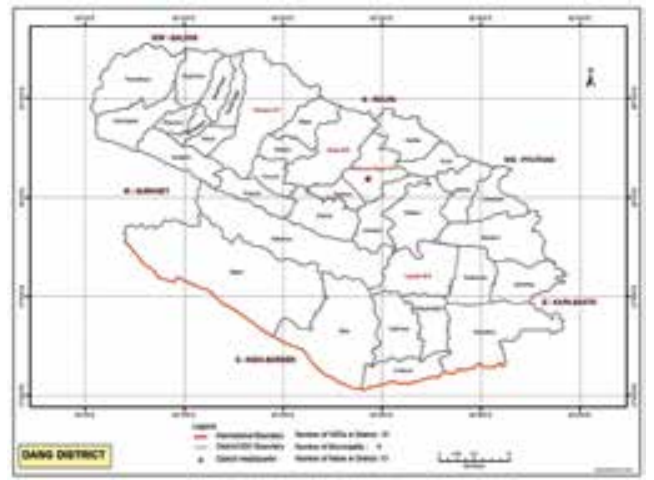

the Siwalik ranges and the Chure hills formed in course of land-drift. It lies on the foothills of the Mahabharata ranges. Some scholars claim that this area was a big jalasaya or lake in the ancient time.

The Tharus trace their origin to Jaimala Fatta, Fateh Singh, Tarran Singh (1303) of Sisaudiya clan of the Rajputs of Rajasthan. The Tharus view that their ancestors were driven out of Chittor by Akbar in 1567 and they were originally Rajputs who lost their caste by using intoxicating liquor and rearing of fowls (Pandey, 1997, p. 87). Ishwar Baral has mentioned that in the $12^{\text {th }}$-century the Rajputs of Chittor sent their women folk to the hills of the Himalayas due to invasion of the Muslim sovereigns. The women awaited their husbands for a long time. But when they did not come to get them back, they adopted their servants at service as husband. The progenies of such unions became the Tharus (Malhotra (ed.), 1969, pp. 160-161).

\section{The clans}

The males belonging to a particular clan are descendants of particular ancestors, who may be of 'Shaman ancestors', 'a Ghost', 'a Spirit' or a 'tot'. The clan in exogamous and patrilineal. Its distinction 
are important on two occasions:

- While fixing wedding arrangements

- At any religious-shamanistic practices (Rajauria, 1997, p. 165 )

\section{Symbolic values behind art in the animistic practices}

The Tharus believe that each and every aspect of nature are the dwelling place or fetish of the spirits who are associated with their daily activities and their social life. In order to please them, they pray and offer ritualistic sacrifices so that they may acquire protection, happiness and fortune for their community and avoid havoc and misfortune.

\section{The art in the animistic practices and associated symbolic values}

Generally a Tharu house is made up of bamboo, plastered with mud and decorated with various designs. The houses are thatched-roof, or khar or elephant-grass is used. If they are economically self-sufficient, they use tin or tiles as roof for single-storey houses.

The Tharus have a traditional belief that their houses should not be built double-storied. They believe that evil

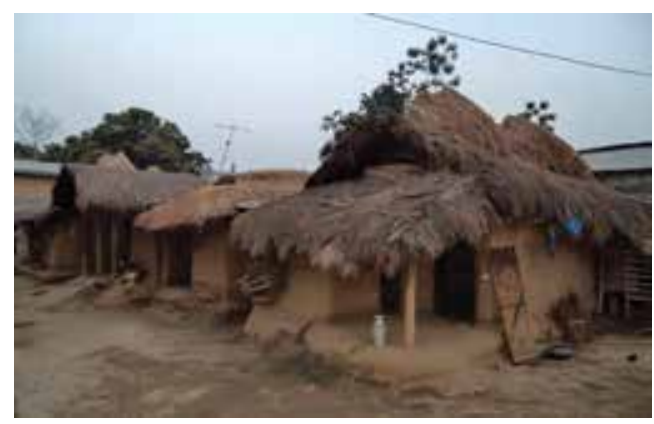

Traditional single-storey houses constructed facing north and south spirits, and ghosts will occupy the ground floor, if a house is double-storied.

They apply their own local method of construction using natural resources for the construction. Their houses do not have windows at all, instead of small holes. This is also based on traditional belief that it would not allow mosquitoes to enter. Besides, their houses are full of smokes, so as to stop insects and mosquitoes to get inside. It is worth noting that in the earlier decades, the Terai region was malaria infested areas.

The Tharus of Dang and Deukhuri to this day are the firm believers of the fetish form of worship. Therefore, each and every household comprises of Devarar (worship-room). Inside a Devarar, one can see numerous fetish. The Devarar is the dwelling place of the spirits or deities.

The fetish within the Devarar itself looks like a piece of art for those who have no idea what they are meant for.

The fetish, located inside a Devarar or worship-room are as follows:

1. Betko: Used by Guruba to drive away evil spirits.

2. Bachi: Used during the time of marriage by the Guruba or Gurau.

3. Thaili: A handwoven bag to store needed materials for worship

Traditional Household Structure of the Tharus

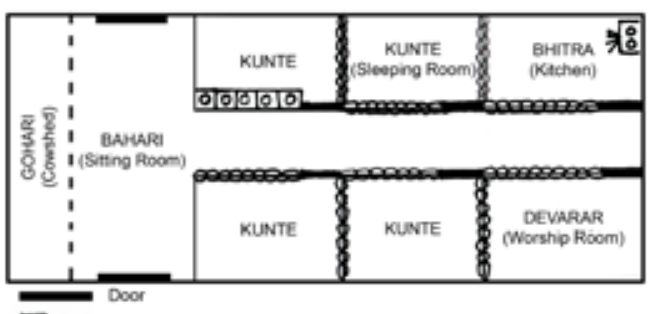

[으 Dahari or Kunti (store places constructed as partisan walls) 


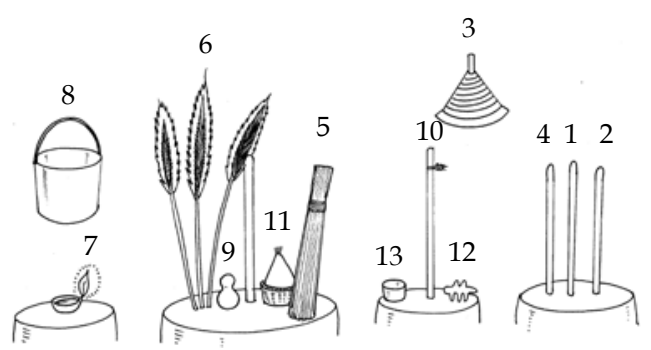

The fetish, located inside a Devarar or worship-room

\section{Junti: An iron rod}

5. Kucho: A broom that is changed after every Dashara festival.

6. Peacock feathers

7. Diya: A lamp lighted with oil

8. Gabali: Used in pouring milk to the deities.

9. Biwakshya: A deity who would bring back missing cattle.

10. Gharwa: Numbers of 'sacred' symbols within the devarar varies, Gharwa is worshipped in case of illness.

11. Maiya: A deity worshipped for protection or 'rakshya'.

12. Dhancho: Usually stolen or brought from another village.

13. Dahari: Used to keep filled with granary so that grains could be gained abundantly.

\section{The local art and symbolic values}

\section{The Fetish Gharwa}

Gharwa is made of clay in shape of a horse. It is worshipped in case of illness. Sacrifices in form of pigs, fowl, and chicken are offered in order to please the spirit. It is very much sacred in the contemporary culture of the Tharus of both Dang and Deukhuri.
The Legend: During the Mahabharata Epic age, a Tharu King called Dangisharan used to possess a female flying horse with magical potency. During the day it takes Dangisharan to elsewhere. At the night the horse turns into an Apsarā (celestial nymph) and leaves for Indralok (heavenly abode) with a pledge to be back the next day. During the Epic age, Dangisharan fights the combat from the Pandavas' side. During the combat as the swords of the Kauravas and Pāndavas collide for the first time, a spark emerges and the Horse gets relived. It leaves for heaven for good. In memory of this legendary horse, the locals use to make 'Gharwa', a horse-shaped art object (fetish) and worship it. In Dang, a mound known as Dangisaran Mound is located, where ancient bricks and Mugal coins have been found.

\section{The fetish Bairakshya}

The Fetish Bairakshya is made of clay. It is placed inside the Devarar (worshiproom). It is seen in the 'Marawa Than' (community worship place) of the Tharus of Dang also.

S. K. Srivastava in his book 'The Tharus: A study of Cultural Dynamics', mentions that during the Mahabharata period a vast region of the Terai was under the Videhas. They were exceptionally famous for their cattle wealth. Even today domestication of animals is the main occupation of the Tharus and Ahiras or the Abhiras of western Nepal. Cattle is the means of livelihood for the Tharus since the times immemorial.

The deity Birakshya is regarded as the protector of cattle. The Birakshya protects cattle and also multiplies them. 
If the deity is angered, it may lead to the death of cattle.

During an interview with Laxman Chaudhary of Bragatti, he responded that in case of missing a domestic animal, if the Bairakshya is prayed with full devotion, the animal would wander back unless not devoured by wild animals.

\section{The fetish Maiya}

Maiya is a spirit symbolized by an iron form. Conviction is that the spirit resides on it and if this 'sacred one' is infriated, havoc prevails over their household. They offer sacrifices of pig, goat, sheep as well as rakshi (home-made alcohol), and jad (fermented rice-beer). Maiya is worshipped twice a year.

\section{The fetish Dhancho}

Dhancho is made up of iron. This spirit protects from burglary. It accepts animal sacrifices. Interestingly, this deity is carried off or brought from another gaon or village and placed in own's Devarar.

During an interview with Shivaram Tharu of Dang, he brought to light that since he was the eldest son of the family, he was expected to bring a 'Dhancho' needed for their 'Devarar'. On one dark night, he went to the nearby village and stole 'Dhancho' from someone else's house. Then he have had installed it at his 'Devarar'. To a question by the author whether he would think it right to steal, he replied that it has been their belief and custom that has been passing down from generation to generation. This is how they would protect themselves from burglary.

\section{The Fetish Bahari/Dahari}

Dahari or Bahari is actually a granary of the Tharus. Inside the Devarar a miniature of the Dahari is formed and grains are stored. The spirit would provide them with abundant of harvest.

Number of the deities inside a worship-room would vary in each household.

\section{The fetish Suchi}

The Tharu community also possess spirits that are considered to be very stern. They would not accept blood sacrifices, nor would accept any offerings of alcohol. The Tharus of both Dang and Deukhuri keep this sort of spirits outside their houses.

Suchi is regarded as the sister deity of Maiya. It would not accept animal sacrifices and alcohol. Therefore, It is offered with fruit, milk and water. Those who intake alcohol and are carnivorous, are not allowed to touch it. Usually a separate house is built for it on the backward of a house. It safeguards the family, especially children from illness.

Chakri and Maiya are sisters of Suchi but they accept sacrifice of animals and alcohol. Hence, they are housed inside the house.

Bhukus and Kapakshya are other deities responsible for protection of the house. In some household images of snakes are kept to shield from outsiders.

\section{The fetish community Bhumiyar worship in Dang}

In the Tharu community of Dang, they perform a worship in a place known as 'Bhumiyar Than'. This than or community worship place exists in every ward. Each group in a ward is formed with 50 to 70 people. For the worship of the Bhumiyar deities, each and every household of the ward contributes 


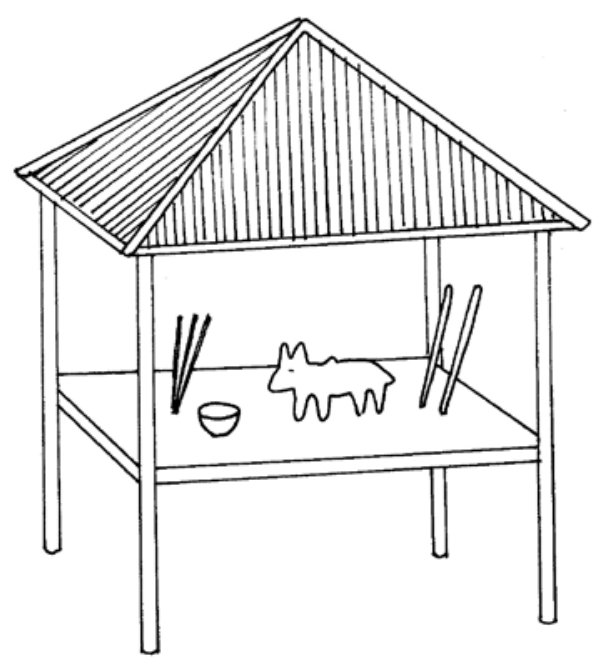

Deity Suchi

pigeons, roosters, hens, alcohol, grains, etc.

The ritual takes place twice a year. The head of the village termed as the Matau performs pooja or ritual. After conclusion of the ritual, a feast is held. The purpose of the ritual is to protect the community from natural calamities such as fire, floods, earthquakes and epidemics.

This kind of community worship also takes place in Deukhuri at the 'Marwa Than'. The 'Marwa Than' comprises of wooden fetish with finger like shape. It is a home place of numerous spirits. The community ritual is conducted by the Guruwa (the mediator between eternal abode and the ephemeral world). The Guruwa and the locals of the ward would come up with needed materials. The main purpose of this ritual is to safeguard the entire community from epidemics and natural calamities and to ensure plenty of grains and cattle.

These Marwas and the wooden carved posts represent different catagories of spirits/deities.
1. Anna Devata: The spirit of the harvest

2. Jhytha Bhumi: The spirit of the earth

3. Bhayanti Devi: The spirit that would safe-guard children.

4. Baharara: The spirit that would protect livestock.

5. Ghore Chandi: The spirit that would protect from epidemics and natural calamities.

6. Bahari: The spirit that would bless with good harvest.

7. Birakshya: The spirit that would drive back missing cattle, if remains alive.

8. Bhutwa: The spirit of the village that would dwell in the nearby jungle and it would look after the entire village.

\section{Other fetish}

Other fetish are also seen in kitchen gardens and small farms that preserve farms. They comprise of crudely designed wooden poles.

\section{Maghi festivity and art}

Maghi is celebrated during the month of Magh (January/February). During this period, walls of houses are decorated with paintings.

These murals are handiworks done by local male and female artists. These murals are meant for temporary period. The murals depict eppic tales related to lord Krishna and the Pandavas.

The wall painting is kept remain on the walls for around fifteen to twenty days. During these days, neighbors would gather and listen to the tales about Lord 


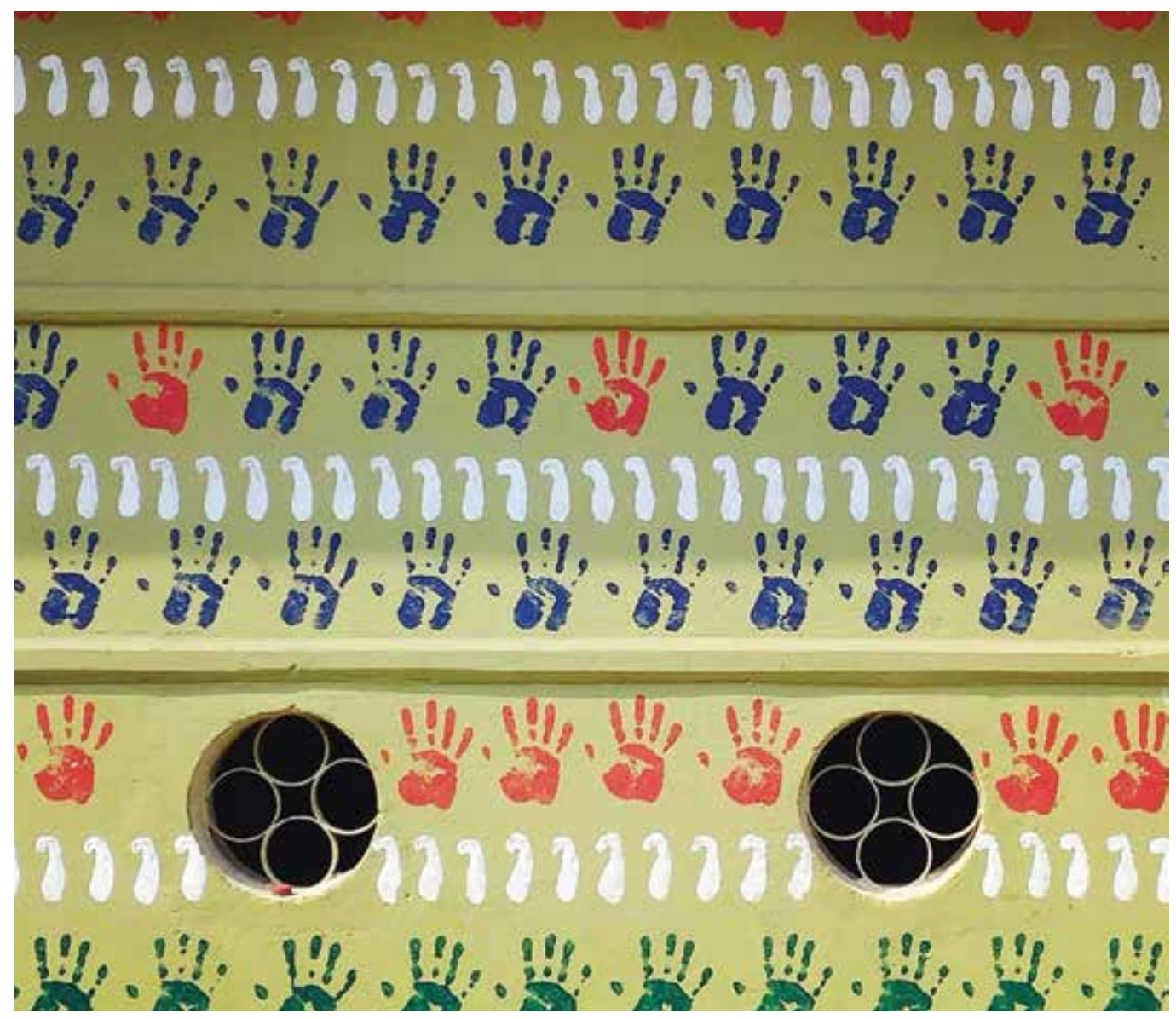

An example of Tharu mural art

Krishna and the Pandavas. These murals, created by the local artists with no formal knowledge on art look extremely captivating.

\section{Conclusion}

Symbolic Values behind Art in the Animistic practices among the Tharus of Dang and Deukhuri are associated with their daily life. They believe that it would impart them with vigour to survive against hardship of life and harsh nature. They firmly believe on their longingness for long life, good health, sturdy children, ample rain, good harvest, multiplication of cattle, access of the deceased to heavenly abode would be acquired through the worship of sacred deities or spirits.

Their entire life is guided by animistic religious beliefs and practices that helps in bringing about social unity and harmony and social order in their lives. For outsiders, the local fetish (object) made and worshipped by the Tharus may have no significant symbolic value 


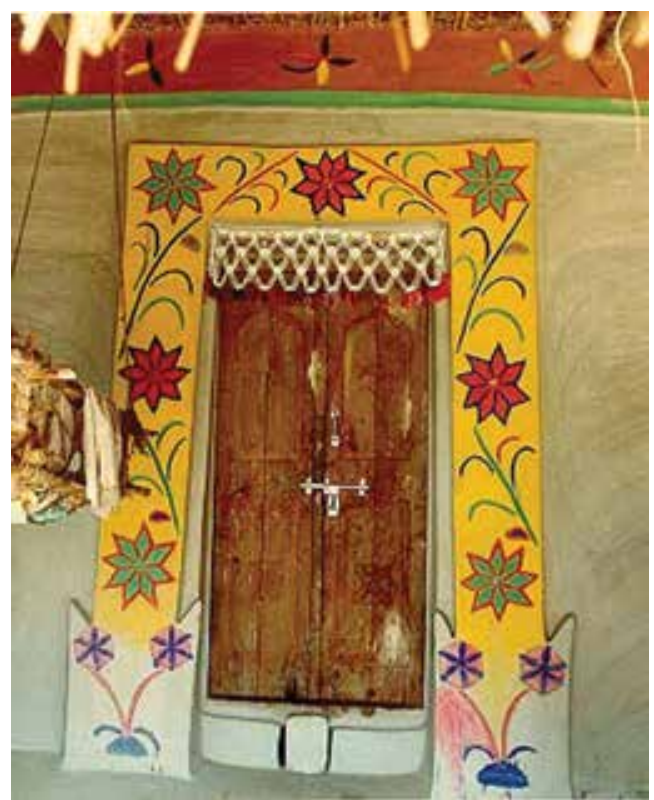

An example of Tharu mural art

or meaning, but, may consider such creativity as a local handicraft or an object. Conclusively, these crude pieces of objects or fetish have great symbolic values in the animistic practices among the Tharus of Dang and Deukhuri

\section{References}

Note: Since this research is based on first hand information or data collected in course of research activity carried out in the southern region of Nepal, numerous references have not been cited.

Alfred, Lang. (1887). Myth, Rituals and Religion, Vol. 1.

Drone P. Rajurya. (1971). Tharus of Dang and Social Context. Kathmandu: Heritage Press.

Haddon, Alfred C. (1906). Magic and Fetishism. Cambridge Univ press, UK.

J. C. Nesfield. Description of the Manners, Industries, Religion of Tharus and Bogsa Tribes of Upper India. Calcutta, Review. Vol. XXX- I (1885).

Kunwar, Ramesh Raj and Acharya, Pramila. (1997). Tharu Women: Traditional Products Modern Market Products. Phase 1. Unpulished Project Report, SAATHI, Nepalgunj.
McDonaugh, Christian. (1984). The Tharus of Dang: A Study of Social Organization Myth and Ritual in West Nepal. D. Phil. Thesis, Oxford University.

Muller Baker, Ulrike. (1993). Tharus and Pahariyas in Chitwan: Some Obervations Concerning and Questions of Multiethnicity in Nepal. in Gerard Toffin (led) Nepal Past and Present, New Delhi: Sterling Publishers.

Pandey, Ram Niwas. (1997). Making of Modern Nepal. New Delhi: Nirala Publication

Pyakuryal, Kailash. (1982). Ethnicity and Rural Development: A sociological Study of four Tharu Villages in Chitwan Nepal. Ph.D. Thesis Michigan State University.

(www.fetism.org) 